\title{
Scévole de Sainte-Marthe, Euvres complètes: I. Euvres de jeunesse, Les Premières Euvres (livre I)
}

Dario Cecchetti

\section{(2) OpenEdition}

\section{Journals}

\section{Edizione digitale}

URL: http://journals.openedition.org/studifrancesi/5592

DOI: 10.4000/studifrancesi.5592

ISSN: 2421-5856

\section{Editore}

Rosenberg \& Sellier

\section{Edizione cartacea}

Data di pubblicazione: 1 septembre 2011

Paginazione: 399

ISSN: 0039-2944

\section{Notizia bibliografica digitale}

Dario Cecchetti, «Scévole de Sainte-Marthe, Euvres complètes: I. Fuvres de jeunesse, Les Premières

Euvres (livre I)», Studi Francesi [Online], 164 (LV | II) | 2011, online dal 30 novembre 2015, consultato il 13 janvier 2021. URL: http://journals.openedition.org/studifrancesi/5592 ; DOI: https://doi.org/ 10.4000/studifrancesi.5592

Questo documento è stato generato automaticamente il 13 janvier 2021.

\section{(c) (i) $\odot$}

Studi Francesi è distribuita con Licenza Creative Commons Attribuzione - Non commerciale - Non opere derivate 4.0 Internazionale. 


\title{
Scévole de Sainte-Marthe, CEuvres complètes: I. CEuvres de jeunesse, Les Premières Cuvres (livre I)
}

\author{
Dario Cecchetti
}

\section{NOTIZIA}

SCÉVOLE DE SAINTE-MARTHE, CEuvres complètes: I. CEuvres de jeunesse, Les Premières CEuvres (livre I), édition chronologique avec introduction, notes et variantes par Jean BRUNEL, Genève, Droz, 2010 («Textes Littéraires Français», 606), cclxxv-955 pp.

1 Scévole de Sainte-Marthe (1536-1623), amico di Belleau, Baïf e Desportes, ammirato da Ronsard e da d'Aubigné, è testimone importante non solo dello svolgimento della storia della poesia manierista e barocca, ma è anche testimone di un impegno caratteristico della vita civile in Francia durante le guerre di religione. S'imponeva pertanto l'esigenza di un'edizione critica dell'opera omnia, anche perché la raccolta più recente di cuvres complètes risale al 1633 (ne esiste una ristampa anastatica: Genève, Slatkine Reprints, 1971, 2 voll.) ed è per di più incompleta. Ora Jean Brunel si è accinto a tale impresa che prevede sei volumi. Svariati sono i generi trattati da Sainte-Marthe: poesia ufficiale messa al servizio di progetti encomiastici o commemorativi, poesia religiosa, poesia filosofica e didattica, poesia amorosa, poesia di circostanza, lusus e poesia satirica, poesie e prose latine, corrispondenza. L'editore ha adottato il criterio di riprodurre le opere di Sainte-Marthe secondo l'ordine della loro pubblicazione nelle raccolte, così come queste si succedono, e di presentare ciascuna di queste opere nella forma in cui sono comparse la prima volta. Ne consegue che nell'apparato critico vengono segnalate le varianti delle edizioni posteriori.

2 In questo primo tomo sono pubblicati i vers de jeunesse (anteriori all'edizione del 1569). Questi versi giovanili sono, in genere, dei testi liminaires ad opere di altri autori: per esempio, alle Foresteries di Vauquelin de La Fresnaye, a due orazioni di François de 
Némond, alla Médée di Jean de La Péruse, ecc. In alcuni casi, si tratta di composizioni pubblicate autonomamente da Sainte-Marthe, come l'Hymne sur la naissance de François de Lorraine (la prima opera del poeta ad essere pubblicata isolatamente). Abbiamo inoltre la pubblicazione delle Premières Euvres (del 1569) suddivise in quattro libri di Imitations, comprendenti in buona parte traduzioni o imitazioni che Sainte-Marthe ha fatto di poeti neolatini o classici. Oltre alla ricca introduzione, che apporta sia dati concernenti l'opera sia tutta una serie di dati biografici utili alla ricostruzione di un'epoca estremamente complicata, abbiamo una cronologia minuziosa che mette in parallelo avvenimenti storici e notizie riguardanti Sainte-Marthe e la sua famiglia. Accurati sono gli indici (l'indice delle biblioteche, l'indice degli stampatori, l'indice storico, l'indice geografico, l'indice dei nomi). Veramente ricca è la bibliografia. 